\title{
Learning as Changing Identity Investment in Social Practice, Discourse Analysis of a Peer Feedback Activity
}

\author{
Chunxian Zheng*, Xueying Huang \\ School of Foreign Languages, Zhejiang University of Science and Technology, Hangzhou, China \\ Email: ${ }^{\star}$ zhengchunxian@hotmail.com
}

How to cite this paper: Zheng, C. X., \& Huang, X. Y. (2017). Learning as Changing Identity Investment in Social Practice, Discourse Analysis of a Peer Feedback Activity. Advances in Applied Sociology, 7, 64-82. https://doi.org/10.4236/aasoci.2017.72004

Received: January 13, 2017

Accepted: February 25, 2017

Published: February 28, 2017

Copyright (C) 2017 by authors and Scientific Research Publishing Inc. This work is licensed under the Creative Commons Attribution-NonCommercial International License (CC BY-NC 4.0). http://creativecommons.org/licenses/by-nc/4.0/ (c) (i) Open Access

\begin{abstract}
Using discourse analysis and social learning theory (Wenger, 1998, 2000, 2010), this article analyzes the peer interactions of a group of four college learners of English in a peer feedback activity with the focus on the writer, the peripheral participant's learning process. The study also uses ethnographical way to interpret the learners' discourse actions in their participation in the four-member-learning-group as a part of the classroom community of practice. The focus of the analyses is on the practices for understanding how the writer witnesses his identity change in this collective revision and reconstruction activity of the draft. The study witnessed Sun's increased participation in term of increased identity investment through two ways of interaction: core interaction within the CoP practice and boundary interaction.
\end{abstract}

\section{Keywords}

Language Learning, Social Learning Theory, Identity Investment, Community of Practice, Peer Feedback Activity, Discourse Analysis

\section{Introduction}

In this article, we report a research on participation-based learning as an exemplar illustration for learning in the sense of community of practice: EFL students' changing participation in a learning group's peer feedback activity. In order to see whether and how the activity is conducive to Sun, the writer and also underachieved student, we especially concern his changing participation over the whole activity in this group, in which practice of revision and reconstruction of his draft was co-constructed by the participants through different actions, mainly discourse actions, in the face-to-face interaction of the peer feedback activity. This co-construction of social practice through action was mediated by Chinese and English, 
the learners' native and foreign language respectively, and also by the writer's first draft as external representations. The study focused on the practices for understanding how the writer witnessed his identity change in this collective activity, and found Sun's increased participation in term of increased identity investment through two ways of interaction: core interaction within the CoP practice and boundary interaction. The data comes from an out-of-classroom peer feedback activity of a study group of four in a mainland Chinese college.

\section{Community of Practice: A Social View of Learning}

Community of practice ( $\mathrm{CoP})$ is a core concept of the social learning theory proposed by Lave and Wenger (1991), and developed by Wenger (1998, 2000, 2010) and Norton (2001), Norton and Toohey (2011). It is inspired by anthropology and social theory (Wenger, 2010: p. 179) and attempts to develop accounts of the social nature of human learning. It does not exist by itself but arises out of learning, and is a concept tool to think about learning in its social dimension, a perspective that "locates learning, not in the head or outside it, but in the relationship between the person and the world" (ibid), in Vygotsky (1978) term, in the interpersonal relationship, in which human beings are social persons in a social world. It is the simplest social unit that has the characteristics of a social learning system, and can be viewed as a simple system. In this system, learning is viewed as both the production of social structure and that of identity, respectively reflecting its collective and individual sides.

By saying learning is the production of social structure; it means learning is a process of active and dynamic (re)negotiation of meaning in the practice (Wenger, 2010: p. 180). That is, in the practice of mutually engagement, a past collective learning experience cumulates into a social structure, which, then is adapted implicitly/tacitly by the participants and shape the practice; meanwhile this structure is adopted and transformed through the participants' (re)negotiation in practice. In this sense, learning produces a social structure, which is informal and dynamic. And this informal and dynamic social structure among the participants is what a $\mathrm{CoP}$ is, in which learners, as actors and agents, engage in practice through active and dynamic negotiation of meaning, implying "an improvisational logic that reflects engagement and sense-making in action” (Wenger, 2010: p. 180).

On the other hand, as the production of identity, learning is a process of interplay or (re)alignment between socially defined competence and personal experience of knowing (Wenger, 2000: p. 227; 2010: p. 183). This competence, known as "the regime of competence" is a set of criteria and expectations by which participants recognize membership, including knowing what the CoP's enterprise is, being able to engage productively with other participants, and knowing how to use appropriately its repertoire of resources (Wenger, 2010: p. 180). And knowing is “a matter of displaying this competence" (Wenger, 2000: p. 226). According to Wenger (2000: p. 227; 2010: p. 180), when a newcomer participates in a CoP, mostly the competence is pulling the experience along, for mostly the newcomer is learn- 
ing from other members through "legitimate peripheral participation" (Lave and Wenger, 1991), a way a newcomer get access to practice. Conversely, when a participant learns something new from other CoPs, introduces it into their own one, and is adopted by it, his experience is pulling the CoP's competence along. Through it, the CoP's boundary is extended, and the CoP is advanced. This is what Wenger $(2000,2010)$ termed the successful boundary process. And the contradiction emerged among the learners in their co-participation in the practice can be viewed as a boundary interaction of the CoP, wherein different perspectives encounter with each other.

Whether competence pushes experience along, or the other way around, learning entails interplay or (re)alignment between these two aspects, with "each moment of learning being a claim to competence" (Wenger, 2010: p. 180). The success of this claims to competence means being able to display competence and become a competent person. And the more competence one can display the more knowledgeable and powerful he or she is. In this sense the process of interplay or (re)alignment is an experience of strive for an integration of multiple knowledge or ability, what Wenger termed "knowledgeability" (Wenger, 2010: p. 181), and struggle for identity on the part of the individual of the CoP. In this process, the individuals, as actors and agents, can decide and modulate their degree of identification according to their need to belong to the CoP, and the need to be accountable to its regime of competence, "Through this process of identification, the practice, the community, and one's relationship with it become part of one's identity" (Wenger, 2010: p. 181). So, identity "reflects a complex relationship between the social and the personal" (ibid). It is a trajectory of learning, reflecting the learner's degree of identification with the community at each moment's claim for competence through the journey of practice landscape. Learning is a social becoming.

This focus on the social aspect of learning means an emphasis on "the whole person" (Lave \& Wenger, 1991: p. 53; Wenger, 2010: p. 181) as a social participant and a meaning-making entity for whom the social world is a resource for constituting an identity, rather than just a cognitive entity. In Allwright (2005) term, cognitive, affective and social aspects work together when participants engage in practice. In this ecological perspective of whole person involvement, learning is becoming a certain person rather than just acquiring skills and information. That is, becoming "a knower in a context where what it means to know is negotiated with respect to the regime of competence of a community" (Wenger, 2010: p. 181).

The above account reveals the interdependent and constitutive relationship of the production of structure, collective aspect of learning, and that of identity, the individual aspect of learning. In addition, it also reveals the co-emergence of two processes of learning in the $\mathrm{CoP}$ sense: the core interaction process within a CoP and its boundary process. In the former learning process, what the learners do is mainly honoring the community's own learning history, and the CoP remains a progression on its own. In the latter process, a CoP may encounter different perspectives. And if an alien perspective is adopted, it brings something new to 
the CoP, thus its boundary is extended. These two learning processes are complementary, potentially pushing an in-depth evolution of the CoP and an innovative development of it respectively. And a vigorous $\mathrm{CoP}$ can well balance the acts between honoring the history of the practice and shaking free from it by bringing something new to the CoP. Coping with this double bind is often only possible through boundary process, that is, "communities interact with and explore other perspectives beyond their boundaries" (Wenger, 2010: p. 180).

And in the interplay of learning experience and social competence, whose experience can pull the competence of the CoP? Wenger seems implicitly attributes this role to the full participant $(2000,2010)$. In this study, I find the peripheral participant can also make this contribution.

\section{Previous Study on CoP Sense of Language Learning}

The concept of CoP has been widely applied into various fields. And in the educational domain, the concept has been interpreted differently, producing different research focuses. Among them, two types of literature are prominent: one focuses on situated cognition and the other on social transformation. In the first case, researchers interpret the social character of CoP learning as "a small aura" (Lave \& Wenger, 1991: p. 48), a specific social context as a condition on which learners develop their situated cognition. Studies belong to this category tend to concern the learners' technical growth, that is, cognitive development or academic achievement in the social context (see, Retna \& Ng, 2016). In the second case, researchers interpret the social character of CoP learning as an identity construction process. Studies of this category mostly concern how learners make use of others' resources or how LPP can work (see Hou, 2015; Odonnell \& Tobbell, 2007; Eberlea, Stegmannb, \& Fischerb, 2014).

In the field of second or foreign language learning or education, studies revolving around the above first perspective usually focus on how the language learners acquire an aspect of their second or foreign language in a social learning context over a long period of time, for example, on how the novice learners' linguistic or interactive competence developed over a long period (Cekaite, 2007; Hellermann \& Cole, 2009). And studies belong to the above second perspective vary in their focuses, with some focusing on the factors contributing to students' (non)participation in classroom activity (Norton, 2001; Morita, 2004), on the possibilities and limits of a teaching curriculum that helped the learners' access membership in one community but remained excluded from legitimate membership in others (Warriner, 2010), on how the nonnative English speaker seminar empowered the TESOL students and how intervention helped reinforce their empowered selves in their journey from LPP to fuller participation (Samimy et al., 2011), on the investigation of the factors that contributed to the perceptions of (non)legitimation of the learner's identity and the important role co-construction played in the process of the two musicians' attempts to learn Quichua (Back, 2011), and on how a female participant's identity was socially constructed, and how her investment in the social activities helped her gain LPP 
and affect her English improvement in academic and non-academic settings (Lee, 2014). All these studies were conducted in a longitudinal way (e.g. at least a term) with the focus on the core interaction within the CoP with no contradiction among the participants or with contradiction among them but no solution to it. $\mathrm{Wu}$ (2005) depicted an ideal CoP sense of learning in their EFL environment, where a student-centered learning curriculum was explored and various contradictions got resolved, but his focus is mainly on teacher's development throughout the project. There is no study conducted to examine an ongoing interactive learning process through discourse analysis of the ongoing interactive activity, with the focus on how student learners negotiate their solution to the contradiction among them at the boundary as well as how they conducted their core interaction within the CoP and created LPP for the novice, to explain how cognitive, social and affective factors may work together to contribute novice learners to change their participation in term of identity investment over an activity process. So this article attempts to fill in this blank to see how LPP is structured for Sun, the FL novice learner, and how he negotiated his identity in the practice within the CoP and at its boundary in an out-of-classroom group peer feedback activity.

\section{Methodology}

This study analyzed the peer discourse interaction in a learning group of four undergraduate classmates at an average high school in China: Sun, Yao, Lin, and Tu in their pseudonyms respectively, all were engineering students at their second semester, who were roommates as well, studying for a spring semester class in a course of College English, in which this activity was a normal step for their writing task. Specifically, this writing task was as follows: After finishing a text about an English name story in class, the students were assigned a composition of name stories after class. Two drafts were required. After they had finished the first draft, they submitted it to their teacher. The teacher did not make any feedback but copied the original draft before distributing them back to the students for them to conduct peer feedback activity, thereafter students wrote their second draft and submitted it to their teacher. During the process, the teacher chose a few groups to observe their peer feedback learning activity.

The learning group formed at the beginning of the first semester, and its goal was to conduct various cooperative learning tasks. And the purpose of this activity was to assist Sun to fulfill the revising task. The four, sharing a dormitory, knew each other well and were close friends both inside and outside of the academic context. Of them Sun was one of the unachieved students as far as the subject of English was concerned, who had passed virtually none college English examinations till then. Yao was the class representative of the College English course and was most authoritative in this course in their roommates' eyes. Lin and Tu were close to Yao in English proficiency judging from the examinations' scores.

The peer feedback activity of this group was held on a weekend morning, when both the four students and their teacher didn't have class. Before the formal revision activity and before they started to record this formal activity, the group 
members negotiated the role of the recorder. Sun, the writer presented that his English proficiency was too lower to assume this role, though he was supposed to undertake it as the writer of the original draft. The result of their negotiation was that Yao take up the role, for he was the representative of the College English course and was naturally assumed to be the most adequate one. Then, the four members of the group went to the desk and positioned themselves in such a way: Yao sat at the desk and the other three stood beside him, with the draft put on the desk before Yao, so that it could be easily read by all of them.

Most of the time over the activity, they lowered their heads reading it during the discussion. But occasionally they would raise their heads for relaxation talk after one episode was finished. So discourse of the activity was mainly comprised of what Sawyer and Berson (2004) termed "mediated talk", talk mediated by the learners' native and target language, as well as the first draft of writing, with occasional conversational talk. The typical actions constituting a revision episode was as followed: attention, identification, offering of revision, feedback, and recording, with identification and offering of revision sometimes integrated into one. Attention means they were reading attentively the draft. Identification means identifying a problem in the form of question or statement. Offering of revision means offering a candidate revision. Feedback means giving comment on or explanation of the offered revision, which might result in a reoffering of revision if the comment was negative. And in the case of a positive feedback, it led to the action of recording, which means writing down the negotiated revision proposal.

The whole formal revision process was audiotaped. Meanwhile, the teacher was on the field to observe the activity and took the observational notes. And after the activity, the teacher, assisted by the four students, transcribed the recorded data, based on procedures from De Guerrero \& Villamil (2000) and Gutterrez (2008), to produce protocols for data analysis ${ }^{1}$, with the focus on how Sun negotiated his identity and experience change of it. And when the teacher encountered something puzzling of the discourses, she asked the four students for clarification. In addition, she also resorted to the comparison of the two drafts to help interpret the discourses of the revision activity and see how well Sun, the writer, took up the learning opportunities produced in the activity. So data in this study came from the group's discourse of interaction, the two drafts of Sun, on-the-spot observation and informal interviews.

Data analysis mainly consisted of the following two steps: 1) reading and comparing the two drafts; 2) reading and interpreting the transcription of the interactive discourses assisted by recalling the observation, to see how Sun invested in the revision and reconstruction practice, how he negotiated meaning and identity in his engagement with others through core and boundary interactions, and how this negotiation produced different social structures.

${ }^{1}$ The discourse was divided into 21 episodes, each episode concerned with one topic (one revision task). If a topic is embedded in another topic, the two topics were divided into the same episode. 


\section{Results}

Our report here was on how social structure was produced in the process of meaning negotiation and how identities produced from this negotiation. The whole revision activity was found to comprise of two rounds of sub-activities, with the first round focused on the form revision, and the second on the content one, a reversed sequence against a normal revision activity of a writing task. Our focus was mainly on the changing investment of Sun's identity throughout the activity as a result of both the core and the boundary interactions of the CoP practice. By taking up the learning opportunities emerged in the LPP process, he was observed to be able to engage himself in a deeper practice in the later similar tasks, a sign of increased identity investment. And by turning down the learning opportunities in the resolution of the contradictions among the participants at the boundary interaction, he was witnessed to experience success in competence claiming or identity negotiation. The following process witnessed his changing identification. But since the limitation of space, this article chose only part of the episodes that well revealed this trend of change.

Episode 1

$1 a^{2} Y a o:$ 大家意思意思, 从第一段开始。

(Let's just start our work, from the first paragraph. "She is not-—")

1 b Yao: "She is not-_"

("She is not-—")

2Lin: 这里应该是过去时吧。

(Here it should be the past tense.)

3a Yao: 这句话, 是不是? “she is not called-—”

(You mean this sentence? "she is not called-_")

$3 b Y a o$ : 应该是以前还是现在? 小辉，应该是她现在，还是以前叫那个?

(Is the action of being called a past or a present one? Xiaohui, is he now called or was in the past called the name?)

4 Sun: 我的意思是现在不能叫

(I do not mean now.)

5 Yao: 现在叫名字, 以前是叫她?

(Now she is called this name, and in the past her name was-—?)

6 Sun: 没, 那不是 not 吗, 我写的?

(Don't you see the word "not" which a wrote in the sentence?)

7 Yao: 以前不是叫 Harry, 是不是?

(You mean in the past she was not called Harry? $?^{3}$ )

8 Sun: 她以前不是叫这个嘛。

(Indeed. She was not called this name in the past.)

9 Yao: 以前啊。那你应该说 “she was not called...”

(You mean in the past. Then you should say "she was not called...")

${ }^{2}$ When initially transcribed, $1 \mathrm{a}$ and $1 \mathrm{~b}$ were united in a turn as the No. 1 turn, but in the writing of this article, they were divided into $1 \mathrm{a}$ and $1 \mathrm{~b}$ for the sake of convenience of analysis, for the discourse in the sub-turns functioned differently. So did the latter cases of division.

${ }^{3}$ There is a cultural mistake here in that Harry is a male's name instead of a female in English culture. And the four members failed in recognizing and correcting it. 
10 Sun: 那就 was 吧。

( Then just correct it into “was".)

In this episode, the issue is whether the present tense "is" in the sentence "... for her first twenty-four hours she is called Harry" in Paragraph 1 was correctly used.

It started from Yao's summon to begin the activity (1a), which led to the group members' lowering their head to silently read the draft. Then Yao suddenly read aloud three words "she is not" (1b), which was perceived by Lin as a signal to have identified an error, thus elicited his revision proposal (2). Yao understood Lin but did not make any comment about Lin's revision proposal (3a). Instead he asked Sun, the writer, to clarify the information he intended to convey in this sentence (3b), which engaged Sun in the interactive negotiation of this grammatical meaning, and consequently started a series of negotiation actions in the form of discourse engagement between them ( $3 b-10)$, whereby Yao obtained an access to understanding Sun's abnormal discourse-the word "is"-as an error, and on the basis of which gave a relevant assistance to Sun (9), while Sun took up the learning opportunity provided for him and got an access to understanding the grammatical meaning of the past tense, accepting Yao's assistance (10).

In the process of this grammatical meaning negotiation, Yao's two actions-inviting Sun's engagement (3b) and providing a relevant assistance to Sun (9) - attempted to legitimate Sun's peripheral participation, and Sun's response to them realized this legitimating, thus Yao succeeded in a claim to linguistic and organizational competence in this group as a full participant, making Sun as the legitimate peripheral one. In other word, the two identified with the practice differently, Yao being a master and Sun a novice, hence, the production of a social structure with an unequal or asymmetric power relation between them. But with the progression of practice, it emerged that Sun identified more in a similar episode, as follows.

Episode 5

35 Yao: 她的男朋友的 “uncle who come back”, 唉, “come back”? 这是过去 时还是现在时啊?

(His boyfriend's "uncle who come back", oh, "come back"? Should the tense here the past or the present?)

36 Lin: 应该用 came 吧?

(I think maybe “came" should be used)

37 Sun: came back 嘛

(Yes. “Came back” should be used here.)

38 Yao: came back, 是不是? 过去时?

(You mean "came back", the past tense?)

39 Sun: 是, 哈哈, 讲故事嘛。

( Yes. Hahaha, it's telling the story)

Like Episode 1, this episode is also concerned with the past tense of a verb.

Yao initiated the action of identification and questioned to other members of the group (35), followed by Lin's tentative answer (36). Sun echoed Lin (37), and it caused Yao's questioning to Sun (38), thus elicited Sun's confirmation of and 
justification for his echoing words (39). There was no objection to this revision proposal in this interpersonal process, and it was seen adopted in Sun's second draft, which indicates the success of Sun's (and also Lin's) claim to linguistic competence here in this episode of practice, producing a social structure of more close power relation among Sun, Lin and Yao. In other words, Sun was witnessed to increase his identification with the practice, and this increased investment of identity was realized as his discourse contribution got acquiesced by others, enabling him to participate in the practice as competently as Lin and Yao.

But with the progression of the activity, Sun was sometimes also witnessed to turn down the learning opportunity provided for him and dis-identify himself with the practice, as was seen in the following case.

Episode 8

57 Yao: “her boy friend introduced”, introduced 什么意思啊?

(“'her boy friend introduced", introduced? what's the meaning of it?)

58 (合)：哈哈哈。

(Hahaha)

59 Lin: to his uncle 吧。

(It should be followed by "to his uncle".)

60 a Sun: 要加 to 的? 介绍给谁嘛。

(Should "to" added here when you say someone is introduced?)

60 S Sun: 这里是大写, 这句话要用大写。

(Here should be capitalized.)

$61 Y a o$ : 对对对, 要加 to 的, 介绍。

(Yes. “to" should be added here.)

62 Tu: 什么介绍?

Introduced what?

63 Yao: 把一个女孩介绍给谁嘛

(Introduced a girl to someone.)

64 Lin: introduced to her

(introduced to her)

$65 \mathrm{YaO}$ : 这里是大写, 这句话开头要大写,

(Here should be capitalized.)

66 Lin: to her uncle 嘛。

( $t o$ her uncle)

This episode is mainly about the revision of a grammatically incomplete sentence into a complete one.

In this episode, Yao initiated the identification action and presented a puzzle, but his utterance seemed to ask what the meaning of the word "introduced" was (57). Lin interpreted Yao's question as "what is missing in this sentence?" and uttered his revision proposal (59), which aroused Sun's doubt as to whether the prepositional structure "to his uncle" should be added to this sentence, but his doubt sounded like a question about whether the preposition "to", rather than the prepositional structure "to his uncle", be needed here (60a). So Yao misunderstood Sun's doubt and made a positive answer (61). In other words, Yao's answer might not 
really match Sun's question, but Sun thought it did.

Here we interpreted Sun's utterance as a doubt or challenge instead of an inquiry, based on two facts. One is that in the discourse interaction, he did not stop to listen to the other's response to his utterance, but hurried to switch to the next task immediately, assuming the role of error identification and revision of it all by himself (60b), indicating he became dis-identified with the practice of this task led by Yao and Lin and was initiating the next task of practice controlled by himself at this moment. And this negotiation process produced a social structure of mostly equal power relation between Sun and Yao, that is, the dominant-dominant relationship between them. The other is that in his second draft, we found he did not adopt this revision proposal offered by Lin and Yao.

Another dis-identification was found in Episode 12, as follows:

Episode 12

89 Yao: 好了, 还有最后一句, 大家意思一下。“After that, they will change her name. So now she called Harry".

(Ok. We've only the last sentence unrevised. Cheer up! "After that, they will change her name. So now she called Harry”.)

90 Lin: 好短啊, 要不再加一个。

(How short it is! Maybe we have to add something.)

91 Yao: 我也这么想啊。

(I agree with you.)

92 Sun: 加什么呢?

( What plot can be added?)

$93 \mathrm{Yao}$ : 我不知道哦。

(I don't know yet.)

94 Lin: She went to the airport, 然后就 changed name 什么的。

(She went to the airport, then something happened and she changed name. A plot like that.)

95 Sun: 不要太过分哦。

(Don't make too much revision.)

$96 Y a o$ : 我感觉这篇文章很灵光啊, 简而易改。

(It seems to me this composition is just brief. So it's easy to revise.)

97 Sun: 我以为差耶, 还有什么东西可加的?

(I have thought it's poor. Anything else that can be added to make it longer?)

98 Lin: 还没想好。

(I haven' t plan it well.)

99 Yao: 哎呀, 哎, 没了, 没啥好改的了。就是短了点啉。

(Oh, no, nothing can be added, though it is a little too short.)

100 Lin: 短小精悍。

(Brief and concise.)

$101 \mathrm{Yao}$ : 是否可以恩一下 “暂停” 了。

(Shall we press the "pause" key.)

102 Lin: 不知道䒝。 


\section{(I don't know.)}

This episode is negotiating whether the content of the draft should be revised to make it rich and the composition longer.

It started with Yao's encouragement and summons (89), followed by Lin's identification of a problem (90), which was echoed by Yao (91). Their discourses aroused Sun's question about how to solve the problem (92), which elicited Lin's constructive answer (94). But Sun rejected it (95). In other word, Lin and Yao failed in their claim to content revision competence because of Sun's unwillingness to identify with the kind of practice Lin and Yao designed and dominated. This change of Sun's attitude from positive to negative caused Yao to switch into a complimentary evaluation of Sun's draft (96), which helped resolve his negative perception of or belief in his writing (97a), and promoted his active seeking of revision advice (97b), an evidence of his attempt of re-identification with the practice led by others, and also an evidence of Yao's success of a claim to his communicating and organizing competence.

As for Lin, he seemed cautious of giving advice after encountering rejection, claiming that he had not thought out how to revise (98). So Yao picked up the turn to express his critical comment as a response to Sun's assistance-seeking action, continuing his compliment but repeating the previously identified problem (99). Lin followed up this compliment to further encourage Sun, an affective scaffolding in De Guerrero and Villamil (2000: p. 59) term collaboratively provided by Yao and Lin to create an LPP environment (100). Following to this collaborative encouragement to Sun, Yao asked whether they could stop the activity (101), intending to leave the decision to Sun, the writer himself. But Lin picked up the turn and made an ambiguous response (102), which could be perceived as an indirect suggestion to Sun to further the revision. For, if Yao had really meant to stop, he could have realized it through a direct proposal. Similarly if Lin had intended to stop the activity, he could have uttered a confirmative response instead of a vague one. In this sense, their discourses also served as a signal for them to invite Sun, the writer, to make a decision, an effort of legitimating Sun's deeper participation or identity investment. So the negotiation process of this episode of practice produced a social structure of unequal power relation between Sun and the other two members: Yao and Lin. That is, novice-master relationship.

In addition, the discourses of Yao and Lin here demonstrated their collaborative effort for a claim to their communicating and facilitating competence in the practice. And this effort was seen rewarded when it actually led to Sun's active seeking of content revision, as follows.

Episode 14

110 Sun: 要不要再加一点呢?

(Shall we add some plot to the story?)

111 Yao: 随便你呀, 你要加就加吧。

(It depends on you.)

112 Sun: 加点什么呢? 
( What plot can we create?)

113 Yao: 我怎么觉得你这篇文章短小精悍, 刚刚好啊。哈哈哈, 意思一下。

( I think your composition is brief and concise, not too long and not too short. Hahaha, so let's just go on with our revision work.)

114 Sun: 可以加点什么?

( What plot can we add?)

$115 Y a o$ : 照, 这开头是不是应该把这个内容拉长一点。这一段内容感觉太 短了。主题太短了。

(En, at the beginning of the story, the content can be enriched. This first paragraph seems to short.)

116 Sun: 那应该加一点什么? 还是把简单句稍微写得再...

(Then how to enrich it? Shall we just make the simple sentences more...)

117 Lin: 要么你把那个

( You may add something like...)

118 Sun: 把他/她去接他/她叔叔时候, 那个介绍她心情

(Like when she went to the airport with her boyfriend to pick up his uncle, how she felt, just describe her feeling...)

119 Yao: 表情啊, 那个言语啊,

(her facial expression, her words...)

120 Sun: 她说他/她叔叔把她看成个厨师一样的

( she said his uncle said her name sound like a cook...)

121 Lin: suddenly 表情变了一下嘛。

( Then suddenly her facial expression changed.)

The issue of this episode is the collaborative creation of a plot to be added to the story as a solution to the problem identified by Lin and Yao in Episode 12.

It started with Suns' inquiry about whether to enrich the content (110). Yao let Sun himself to make the decision of it (111), an actual action of his legitimating Sun's deeper participation. So Sun made a follow-up inquiry about what to add (112). And Yao once again made a complimentary comment on Sun's writing (113a), a continuing action of LPP condition creation in the form of encouragement. Meanwhile he summoned everyone to continue the revision work (113b), which elicited Sun's third time active inquiry about a possible plot to be added (114). Then Yao began to give his suggestion of revision (115), elicited Sun's more specific inquiry (116), a sign of his increased extent of identity investment in the practice. Sun's question drove Lin's discourse contribution, but it was incomplete and uttered in a tentative and non-fluent way (117), which created a context for Sun to exert his imagination and made greater discourse contribution (118), an opportunity for him to increase his involvement, and thus investment of identity. And the pause of his utterance gave Yao a chance to further create the plot (119), shaping in a sequence of interchanges a recurrent model of mutually providing each other the opportunity to produce the story (117-121), where an intellectual synergy was seen of their minds in the mutual exploration and meaning and content negotiation, and also the tacit under- 
standing and an intersubjectivtiy in the sense of Rommetveit, (De Guerrero \& Villamil, 2000: p. 53; Ligorio, Talamo, \& Pontecorvo, 2005: p. 358) among them in this plot co-creation, producing firstly a social structure of unequal power relation between Sun and the other two members: Yao and Lin (110-117) where Sun appeared incompetent for the content revision and was seeking advice from the others; and then the social structure of almost equal power relation between Sun and Yao and Lin (118-121), where Sun was witnessed being treated as competently as Yao and Lin in the co-creation of the story content. In other words, Sun's deepened LPP drove his ever-increasing identification with the practice, and thus his rising identity investment, which gave rise to the changing social structure of this practice. And this was witnessed to happen more frequently in the subsequent episodes of activity, as follows:

Episode 17

164 Sun: 要不要写点问她男朋友长得好看不好看哪?

(Shall we add a plot about her asking her boyfriend whether she was beautiful or not?)

...

Episode 18

176 Yao: 这里后面应该是从句了哪? 那后面可以直接用 how

(After it is an object clause, right? Then "how" can be used to introduce this object clause.)

177 Sun: what, what she is today. 今天她怎么样。

( what, what she is today. It means how she feels today.)

178 Lin: 或者 whether she is

(Or use "whether she is...")

179 Yao: 哦, whether, 是说她是否够漂亮了。

(Oh, whether, Does it mean whether she is beautifur?)

180 Sun: whether she is...

(whether she is...)

181 Lin: 应该不是问她漂亮吧? 应该问他打扮得怎么样。

(What she asked is not whether she is beautiful, but whether she dresses up well.)

182 Sun: 男女有没有搞错啊, 打扮得不妥吧。

(Are you discussing she or he? I mean whether her dressing is decent enough.)

$183 \mathrm{Tu}$ : 问那么多漂亮干什么?

(Why ask so much about beauty?)

$184 \mathrm{Yao}$ : 问什么?

(Then ask what?)

185 Sun: 你再问一下打扮得有没有不妥。

(Ask whether she dress up decently.)

186 Yao: Asked her boy friend, 恩, 应该什么? 就是说问她的男朋友关于她 的打扮, 是不是?

(asked her boy friend, en, what? Something about her dressing up, 
right?)

187 Sun: yes.

yes.

188 Yao: Asked her boy friend about her...?

(Asked her boy friend about her...?)

189 Lin: Dress

(Dress.)

190 Yao: 用 about?

(Use “about"?)

191 Lin: 不会吧。

(No.)

192 Yao: 什么, 用 about, her dress, dress 啊?

(What? Use "about", her dress, dress?)

193 Sun: Dress。

(Dress.)

In Episode 18, they were creating another plot to enrich the content. It actually started from Sun's proposal in Episode 17 (164), when he proposed to enrich the story plot by writing something about the beautifulness of the girl (164), which did not get prompt responses from others because at that moment they identified a linguistic error and were committed to its revision. Not until they had completed this linguistic error correction task did they respond to Sun's suggestion.

It started with Yao's analysis of a sentence structure, and offering of a revision proposal (176). This proposal was disagreed by Sun, and he presented his own (177), which was further challenged by Lin, who also offered his own (178). Finally the sentence structure offered by Lin was adopted by Yao, who then engaged himself in the content revision work in response to Sun's previous proposal (179) that is, adding some description of the beautifulness of the girl or her dressing. It aroused Sun's thinking aloud (180), and Lin's challenge, offering his own revision version (181). Sun then used a more specific word to support Lin's revision advice (182), a sign of increased identity investment in the practice within the CoP. Meanwhile Tu also presented his disagreement with Sun's original "beautifulness" version of the revision proposal (183), which facilitated Yao to make an inquiry (184), and elicited Sun's answer in the form of repeating his revised version (185), a symbol of his adapting to the CoP. And this revised version was finally agreed to be recorded as a product (186-193), indicating Lin's success in his claim to competence for content creation.

Here in this content negotiation process, we see Yao's revision proposal as a supportive response to Sun's initial proposal was denied by Lin, which made Sun to change his idea and accepted Lin's revision suggestion and further specified this revision version, which finally got approved by others, producing a social structure of mainly unequal power relation between Sun and Lin, where Sun took up the learning opportunity provided by Lin and was trying to identify with the practice led by Lin in this LPP environment. But then a problem occurred, 
resulting Sun to change his idea again, as is seen in the following episode:

Episode 20

199b Yao: ... whether her dress is 什么什么优雅, 典雅, 啊, 太难了, 这个 单词。

(... whether her dress is something like elegant, or graceful. It's a too difficult word.)

200 Sun: 是什么 “妥不妥” 啦!

(It's about whether her dress is “妥不要” [ decent].)

201 Yao: Whether her dress is comfortable. “comfortable” 是很 “舒服的”?

(You mean whether her dress is comfortable. "comfortable" means “舒服的”?)

202 Tu: comfortable?

(Comfortable?)

203 Yao: 恩。 suit 和 comfortable 都可以的嘛。

(Yeah. I think "suit" and "comfortable" are both appropriate here.)

204 Lin: “comfortable” 是 “舒服” 的意思唉!

(“comfortable” means“舒服的” in Chinese.)

$205 \mathrm{Yao}$ : “你看上去舒服” 嘛, 差不多的, 可以用的。

(Yeah, indeed. Here the meaning is “You look” “舒服的”)

206 Sun: 是阿, 差不多的。

(Yeah, That's the meaning I want to convey.)

$207 \mathrm{Yao}$ : 差不多的, 可以用的。

(So "comfortable" is applicable here.)

208 Sun: 典型的, 典型的中式英语。

(It's a typical Chinglish case.)

209 Yao: 那就是 suit 了。

(In that case, use "suit".)

210 Sun: beautiful 算了。

(Use "beautifuP", "beautiful" is better.)

211 Lin: 还是 beautiful 最简单。

(The word “beautifup" is most concise.)

212 Yao: 哦, 好的。

(Ok. Use “beautifup".)

$213 T u$ : 要符合孙的理想。

(Your choice of the word must base on the meaning Sun intends to convey.)

This episode was indeed the continuation of the above episode of content co-creation task, focusing on how to translate the Chinese "tuo" into English.

Yao first gave his interpretation (199b). It encountered Sun's disagreement (200), which elicited Yao's another interpretation (201), but it was challenged by $\mathrm{Tu}$ and Lin $(202,204)$. Yao insisted $(203,205,207)$, and Sun expressed his support to Yao's translation (206), leading to Yao's reiteration of his idea (207). But Sun suddenly changed his mind and made a negative comment to Yao's translation (208), which further elicited Yao's transformed version (209). Again it was 
denied by Sun, who re-proposed his initial revision version, that is, creating a plot concerning "whether the girl or her dress is beautiful or not" (210). It encountered Lin's positive comment (211), Yao's acceptance of (212), and Tu's articulation of one of the rule of the revision activity: base the revision on the writer's intention (213). It witnessed the success of Sun's claim to competence for the content creation in this negotiation process where his abnormal discourse got accepted by others, producing a social structure of equal power relation between Sun and the other three members, where Sun experienced greatest identity investment. Meanwhile, it witnessed the fact that Sun's macro writer identity also involved in this competence claim, contributing to his identity construction in the practice.

\section{Discussion}

In this study, we see the changing participation of Sun in term of changing investment of identity through two processes of interactions, core and boundary interaction. In the former case, Sun engaged in the practice as a legitimate peripheral participant, where he mainly used others as a learning resource to cultivate his competence, forming a novice-master relation between him and other member(s) in the negotiation process of the activity, thus producing a social structure of unequal power relationship between him and other member(s). And in the latter case, he expressed his doubt about other's ideas indirectly, as the case of Episode 12 , or directly, as the case of episode 20 , establishing a latent dominant-dominant relation in Episode 12 and master-master one in Episode 20 between him and other member(s), thus producing a social structure of virtually equal power relationship between him and other member(s), with the result of either no identity investment in the practice led by others, as is the case of Episode 12, or increased identity investment in the practice led by himself, as is the case of Episode 20 .

In the core practice of the $\mathrm{CoP}$, to which he was acculturated, his experience was pushed along by the community competence in that he learned from other competent members, achieved an understanding, and then was able to make contribution as a competent member did, as is the typical case embodied in Episode1 and 5 ; and in the boundary practice, he obtained more agency and brought something different to the revision practice, an "abnormal discourse" in Bruffee (1984) term, and in the process of negotiation and renegotiation, this abnormal discourse was adopted and absorbed as part of the CoP regime of competence, as is the typical case from Episode 18 to 20.

Both the core interaction within the $\mathrm{CoP}$ and its boundary interaction witnessed enabling effect in that in both contexts, it is possible for Sun to achieve success of his claim to competence, enabling him to engage in the practice as a competent participant, what Lave and Wenger (1991) termed "a different person" (P53). In the former case, Sun attempted to adapt to the kind of practice led by Yao or Lin through LPP, enabling him to identify with it more deeply, and pushing his identity investment along with the evolution of the CoP. But in the latter case, 
the absorption of Sun's abnormal discourse into the practice means the qualitatively change of the group social structure and the practice's artifact-the revised content. In this sense, we say the boundary process has the revolutionary and innovative effect. These two processes are complementary, in which Sun experienced the double bind or responsibility of honoring the history of the practice and shaking free from it in the dynamic process of the activity. And in Sun's claim to competence, we see the co-work of the cognitive, social and affective factors, as is reflected in Episode 5, 20 and 14 respectively.

\section{Conclusions and Instructional Implications}

In this study, we witnessed Sun's changing identity investment in the social practice of peer revision activity through two interactive ways: core interaction within the CoP practice and the one at the boundary of it. In the former case, Sun, through LPP, was assimilated into the local practice led by its representative members such as Yao and Lin, mostly by taking up various learning opportunities created for him. In the latter case, he challenged the dominant members; dis-identifed with the practice led by them and struggled to dominate the practice by himself, turning down the opportunities provided for him. Both ways were viable to drive Sun to obtain progress. This produces an implication for classroom instruction: while students' rejection of learning opportunity may be a flaw of learning that needs overcoming; as is the case from Episodes 12 to 14, it may also be a signal of their struggle for identity or a voice, as Dunn and Lantolf (1998) said, "failures are not just flaws or signs of imperfect learning but ways in which learners attempt to establish (new) identities and gain self-regulation through linguistic means" (p. 427). In this sense, it is not a negative indicator of classroom learning but a symbol of great potential it may lead to, that is, an innovative potential.

And the study witnessed that this innovative force arose from Sun, the legitimate peripheral participant, as an abnormal discourse initially and finally took effect as this abnormal discourse was accepted through negotiation and renegotiation. This expands Wenger (2000: p. 227) conception of the role of a legitimate peripheral participant being excluded from the innovative contribution to the $\mathrm{CoP}$ into one that any participant may contribute to the introduction of new perspective into the CoP. But this will only occur in a learning community where horizontal instead of vertical responsibility is dominant. It implies the necessity of an open, dialogic classroom environment to discover and include in the curriculum the possible fresh perspectives from students. In addition, it also implies the necessity of broadening the evaluation conception of the quality of the language classroom learning to include multiple dimensions and competences, focusing on the whole development of the student as a person, rather than solely consider whether it contributes the learner's linguistic proficiency. That is to transform the traditionally linguistic knowledge-oriented to competence-oriented assessment practice.

\section{Acknowledgements}

We would like to thank our mentor, Professor Wu Zongjie for his support in the 
process of writing this article. We are also appreciated for the anonymous reviewer of this journal for the revision suggestion. And our appreciation is also given to the students who participated in this project.

\section{References}

Allwright, D. (2005). From Teaching Points to Learning Opportunities and Beyond. TESOL Quarterly, 39, 9-31. https://doi.org/10.2307/3588450

Back, M. (2011). Legitimate Peripheral Participation and Language Learning: Two Quichua Learners in a Transnational Community. Language Learning, 61, 1039-1057. https://doi.org/10.1111/j.1467-9922.2011.00662.x

Bruffee, K. A. (1984). Collaborative Learning and the "Conversaton of Mankind". College English, 46, 635-652. https://doi.org/10.2307/376924

Cekaite, A. (2007). A Child's Development of Interactional Competence in a Swedish L2 Classroom. The Modern Language Journal, 91, 46-62.

https://doi.org/10.1111/j.1540-4781.2007.00509.x

De Guerrero, M. C. G., \& Villamil, O. S. (2000). Activating the ZPD: Mutual Scafforlding in L2 Peer Revision. The Modern Language Journal, 84, 51-68.

https://doi.org/10.1111/0026-7902.00052

Dunn, W. E., \& Lantolf, J. P. (1998). Vygotsky's Zone of Proximal Development and Krashen's i + 1: Incommensurable Constructs; Incommensurable Theories. Language Learning, 48, 411-442. https://doi.org/10.1111/0023-8333.00048

Eberlea, J., Stegmannb, K., \& Fischerb, F. (2014). Legitimate Peripheral Participation in Communities of Practice: Participation Support Structures for Newcomers in Faculty Student Councils. Journal of the Learning Sciences, 23, 216-244. https://doi.org/10.1080/10508406.2014.883978

Gutterrez, A. G. (2008). Microgenesis, Method and Object: A Study of Collaborative Activity in a Spanish as a Foreign Language Classroom. Applied Linguistics, 29, 120-148. https://doi.org/10.1093/applin/amm032

Hellermann, J., \& Cole, E. (2009). Practices for Social Interaction in the LanguageLearning Classroom: Disengagements from Dyadic Task Interaction. Applied Linguistics, 30, 186-215. https://doi.org/10.1093/applin/amn032

Hou, H. (2015). What Makes an Online Community of Practice Work? A Situated Study of Chinese Student Teachers' Perceptions of Online Professional Learning. Teaching and Teacher Education, 46, 6-16. https://doi.org/10.1016/j.tate.2014.10.005

Lave, J., \& Wenger, E. (1991). Situated Learning: Legitimate Peripheral Participation. Cambridge, MA: University of Cambridge Press. https://doi.org/10.1017/CBO9780511815355

Lee, E. J. (2014). Motivation, Investment, and Identity in English Language Development: A Longitudinal Case Study. System, 42, 440-450. https://doi.org/10.1016/j.system.2014.01.013

Ligorio, M. B., Talamo, A., \& Pontecorvo, C. (2005). Building Intersubjectivity at a Distance during the Collaborative Writing of Fairytales. Computers \& Education, 45, 357374. https://doi.org/10.1016/j.compedu.2005.04.013

Morita, N. (2004). Negotiating Participation and Identity in Second Language Academic Communities. TESOL Quarterly, 38, 573-603. https://doi.org/10.2307/3588281

Norton, B. (2001). Non-Participation, Imagined Communities, and the Language Classroom. In: M. Breen (Ed.), Learner Contributions to Language Learning: New Directions in Research (pp. 159-71). Harlow: Pearson Education.

Norton, B., \& Toohey, K. (2011). Identity, Language Learning, and Social Change. Lang. 
Teach. 44, 412-446. https://doi.org/10.1017/S0261444811000309

Odonnell, V. L., \& Tobbell, J. (2007). The Transition of Adult Students to Higher Education: Legitimate Peripheral Participation in a Community of Practice? Adult Education Quarterly, 57, 312-328. https://doi.org/10.1177/0741713607302686

Retna, K. S. \& Ng, P. T. (2016). The Application of Learning Organization to Enhance Learning in Singapore Schools. Management in Education, 30, 10-18. https://doi.org/10.1177/0892020615619665

Samimy, K., Kim, S., Ahlee, J., \& Kasai, M. (2011). A Participative Inquiry in a TESOL Program: Development of Three NNES Graduate Students' Legitimate Peripheral Participation to Fuller Participation. The Modern Language Journal, 95, 558-574. https://doi.org/10.1111/j.1540-4781.2011.01247.x

Sawyer, R. K., \& Berson, S. (2004). Study Group Discourse: How External Representations Affect Collaborative Conversation. Linguistics and Education, 15, 387-412. https://doi.org/10.1016/j.linged.2005.03.002

Vygotsky, L. S. (1978). Interaction between Learning and Development. In M. Cole, V. John-Steiner, S. Scribner, \& E. Souber-Man (Eds.), Mind in Society: The Development of Higher Psychological Processes (79-91). Cambridge, MA: Harvard University Press.

Warriner, D. S. (2010). Competent Performances of Situated Identities: Adult Learners of English Accessing Engaged Participation. Teaching and Teacher Education, 26, 22-30. https://doi.org/10.1016/j.tate.2009.06.003

Wenger, E. (1998). Communities of Practice. Learning, Meaning, and Identity. Cambridge, MA: Cambridge University Press. https://doi.org/10.1017/cbo9780511803932

Wenger, E. (2000). Communities of Practice and Social Learning Systems. Organization, 7, 225-246. https://doi.org/10.1177/135050840072002

Wenger, E. (2010). Communities of Practice and Social Learning Systems: The Career of a Concept. In C. Blackmore (Ed.), Social Learning Systems and Communities of Practice (pp. 179-198). London: Springer. https://doi.org/10.1007/978-1-84996-133-2_11

Wu, Z. (2005). Teachers' Knowing in Curriculum Change: A Critical Discourse Study of Language Teaching. Beijing: Foreign Language Teaching and Research Press. 
Submit or recommend next manuscript to SCIRP and we will provide best service for you:

Accepting pre-submission inquiries through Email, Facebook, LinkedIn, Twitter, etc. A wide selection of journals (inclusive of 9 subjects, more than 200 journals)

Providing 24-hour high-quality service

User-friendly online submission system

Fair and swift peer-review system

Efficient typesetting and proofreading procedure

Display of the result of downloads and visits, as well as the number of cited articles Maximum dissemination of your research work

Submit your manuscript at: http://papersubmission.scirp.org/

Or contact aasoci@scirp.org 